\title{
Lise Öğrencilerinde Siber Zorbalık ve İnternet Bağımlılığı
}

\section{Cyberbullying and Internet Addiction in High School Students}

\author{
Yağmur Sezer Efe 1(D), Emine Erdem 1(D), Birgül Vural 2(ID)
}

1. Erciyes Üniversitesi Sağık Bilimleri Fakültesi, Çocuk Sağlığı ve Hastalıkları Hemşireliği Anabilim Dalı, Kayseri

2. Gaziosmanpaşa Üniversitesi Sağlık Bilimleri Fakültesi, Çocuk Sağlığı ve Hastalıkları Hemşireliği Anabilim Dalı, Tokat

\begin{abstract}
Objective: This descriptive study was carried out to determine the relationship between cyberbullying and internet addiction of high school students.

Method: The research was carried out on 546 high school students who studying in 9-12 grades. In this study getting the permission of the ethics committee and the institution, the data were collected using the Descriptive Characteristics Form for Adolescents, Cyber Bullying and Aggressiveness on the Internet Scanning Scale (CBAISC) and the Internet Addiction Scale (IAS).

Results: Of the high school students, $59.0 \%$ were girls, $54.0 \%$ were in the 9th grade. Of the students, $32.2 \%$ used the internet for 3-5 hours/day on weekdays, $30.2 \%$ used for 3-5 hours/day on weekends, $40.1 \%$ of them used internet to chat on social networking sites (facebook, twitter, instagram, whatsapp, etc.). The mean scores of the being subjected to cyberbullying and being a cyberbully subscales of CBAISC of students who use internet $>7$ hours/day on weekdays and weekends were high. A low level significant correlation was found between the total IAS score and the being subjected to cyberbullying and being a cyberbully subscales scores.

Conclusion: Informative seminars can be organized for students, families and teachers with the cooperation of health professionals and school administrators/staff about internet addiction, risks to the internet, conscious and healthy use of the internet, cyberbullying. In addition, conducting awareness-raising intervention activities can reduce the occurrence of situations such as internet addiction and cyberbullying / victimization.
\end{abstract}

Keywords: Internet addiction, high school students, cyberbullying

Öz

Amaç: Bu tanımlayıcı araştırma, lise öğrencilerinin siber zorbalık ve internet bağımlıı̆ı arasındaki ilişkiyi saptanması amacı ile yapılmışıır.

Yöntem: Araştırma, bir il merkezindeki 9-12. sınıflarda öğrenim gören 546 lise öğrencisi ile yapıımıștır. Etik kurul ve kurum izni alınan araştırmada veriler, Ergenler için Tanıııcı Özellikler Formu, Siber Zorbalık ve Internet Saldırganlığı Tarama Ölçeği (SZisTÖ) ve İnternet Bağımlıı̆ı̆ı Ölçeği (iBÖ) ile toplanmıştır.

Bulgular: Lise öğrencilerinin \%59.0'ının kız, \%54.0'ının 9. sınıfta olduğu, \%32.2'sinin hafta içi 3-5 saat/gün, \%30.2'sinin hafta sonu 3-5 saat/gün internet kullandıkları, \%40.1'inin sosyal paylaşım sitelerinde (facebook, twitter, instagram, whatsapp vb.) chat yapmak için internet kullandıkları belirlenmiş̧ir. Hafta içi ve hafta sonu internet kullanım süresi >7 saatten/gün olan lise öğrencilerinin SZisTÖ Siber Zorba Kurbanı Olma (SZKO) ve Siber Zorba OIma (SZO) alt ölçek puan ortalamalarının yüksek olduğu bulunmuştur. Lise öğrencilerinin İÖ toplam puanı ile SZiSTÖ-SZKO ve SZO alt ölçek puanları arasında düşük düzeyde anlamlı bir ilişki bulunmuştur.

Sonuç: Öğrencilere, ailelere ve öğretmenlere internet bağımlı̆ı, internette yaşanabilecek riskler, internetin bilinçli ve sağlıkı kullanımı, siber zorbalık konusunda sağlık profesyonelleri ve okul yönetimi/personelinin işbirliği ile bilgilendirici seminerler yapılabilir. Ayrıca farkındalık artıııı müdahale çalışmalarının yapılması internet bağımlıı̆ı ve siber zorbalık/mağduriyet gibi durumların yaşanmasını azaltabilir.

Anahtar kelimeler: Internet bağımlılı̆ı, lise öğrencileri, siber zorbalık 


\section{Giriş}

Bilgive kolay ve hızı ulaşma, duygu ve düşünceleri ifade etmeye ortam sağlaması nedeniyle internet, yaşamın vazgeçilmez bir parçası haline gelmiştir. Özellikle Covid-19 pandemisi sonrasında sosyal ortamlar, yüz yüze iletişim gibi birçok yaşam alanları ve yaşam stillerinin kısıtlanması, okul derslerinin bile online eğitim ile yürütülmesi interneti vazgeçilmez kılmıştır (1-3). Türkiye İstatistik Kurumu (TÜIK)'in araştırmasına göre, Türkiye genelindeki hanelerin \%90.7'sinin evden internet erişimine sahip olduğu, nüfusun \%79.0'ının internet kullandığı belirlenmiştir. Bilgisayar ve internet kullanım oranlarının en yüksek olduğu yaş grubunun ise ergenler ve genç yetişkinler olduğu (16-24 ile 25-34 yaş grubu) bildirilmektedir (4). Bilişim teknolojilerinin aşırı ve problemli kullanımı ve ilişkilerin sanal ortamlara aktarıması, ergenlerde internet bağımlılığı ve siber zorbalık gibi ortaya çıkabilecek birtakım olumsuz durumları da beraberinde getirebilmektedir.

Bilgisayar, cep telefonları, internet gibi dijital teknolojinin başkalarını rahatsız etmek amacıyla kasıtı ve düzenli olarak kullanılması olan siber zorbalık, siber zorba ve siber mağduriyet gibi kavramları içinde barındırmaktadır (5-8). Ulusal ve uluslararası düzeyde yapılan çalışmalarda, siber zorbalık ve mağduriyetin ergenler arasında yaygın bir sorun olduğu görülmektedir (9-14). Yapılan çalışmalarda siber zorbalık yapma \%6.3-59.4 (12-15), siber zorbalığa uğramanın ise \%8.7-63.3 (12-15) arasında değiştiği belirlenmiştir.

Bilgisayar ve internet kullanımının yaygınlaşması ile birlikte, siber zorbalığın yanı sıra, ortaya çıkan bir diğer olumsuz durum internet bağımlılı̆ıdır. Türkiye'de lise öğrencilerindeki internet bağımlı̆ğının \%9 olduğu belirlenmiştir (16). Ergenler, teknolojiye daha çok ilgi duydukları ve henüz psikolojik olgunluğa erişmedikleri için interneti diğer yaş gruplarına göre daha çok kullanmakta ve internet bağımlılı̆̆ı açısından risk grubunu oluşturmaktadır (17).

İnternet kullanımının en fazla risk oluşturduğu ergenlik döneminde (18), internet bağımlıı̆̆ obezite, lordoz, kifoz ve uyku sorunları gibi fiziksel sağlık sorunları; sosyal iletişimde azalma, sosyal izolasyon, saldırganlık, öfke, yalnızlık, depresyon gibi psikososyal sağlık sorunlarına yol açabilmektedir $(19,20)$. Sağlık profesyonellerinin ergenleri siber zorbalık ve internet bağımlıı̆̆ının yol açı̆̆ı̆ olumsuz etkilerden koruması büyük bir önem taşımaktadır. Bu nedenle bu problemlerin erken dönemde fark edilmesi, önleme çalışmalarının planlanması için ergenlerde siber zorbalık ve internet bağımlılığının incelendiği çalışmalara gereksinim duyulmaktadır.

Bu çalışma, lise öğrencilerinde siber zorbalık ile internet bağımlıı̆̆ arasındaki ilişkinin belirlenmesi amacıyla yapılmıştır. Bu çalışmada, 1) Lise öğrencileri internette hangi ortamlarda (youtube, twitter...) siber zorbalık ve internet saldırganlığına maruz kalıyor? 2) Lise öğrencilerinin internet kullanım sıkıklarının siber zorbalık ve internet saldırganlığı üzerine etkisi var mıdır? 3) Lise öğrencilerinde internet bağımlıığı ile siber zorbalık ve internet saldırganlığı arasında ilişki var mıdır? araştırma sorularına cevap aranmıştır.

\section{Yöntem}

\section{Örneklem}

Bu tanımlayıcı araştırma, lise öğrencilerinde siber zorbalık ile internet bağımlıı̆ı arasındaki ilişkinin belirlenmesi amacıyla 15-30 Ekim 2020 tarihleri arasında Karadeniz bölgesinde bir ilde il Milli Eğitim Müdürlüğü'ne bağlı liselerde gerçekleştirilmiştir. Araştırmanın evreni, 2020-2021 eğitim-öğretim yllında bir il merkezindeki 17 lisede öğrenim gören 7613 öğrenciden oluşmuştur. Evreni bilinen örneklem hesabı yapılarak araştırmanın örneklemi en az 458 öğrenci olarak belirlenmiştir (\%95 güven aralığı ve \%5 yanılma olasılı̆̆ı). Araştırma basit rastgele örnekleme yöntemi ile belirlenen liselerde (3 lise) 9-12. sınıflarda öğrenimine devam eden, araştırmaya katılmak isteyen ve ebeveyni onam veren 546 ergen ile yapılmıştır. Araştırma sonrası G power'da çalışmanın gücü \%99 olarak hesaplanmıştır. 


\section{İşlem}

Erciyes Üniversitesi Sosyal ve Beşeri Bilimler Etik kurul (No:76/2020)'undan ve çalışmanın yapıldığı ildeki İ Milli Eğitim Müdürlüğü'nden kurum izni (27001677/44/20812138) alınan bu araştırmada, araştırmacılar verilerin toplanması için basit rastgele örnekleme metodu ile belirlenen liselere giderek okul yöneticileri ile görüşmüşlerdir. Araştırmacılar okul yöneticilerine çalışmanın amacını ve öğrencilere uygulanacak anketlerin Google formlar üzerinden uygulanacağını iletmişlerdir. Işbirliği yapmayı kabul eden ve çevrimiçi veri toplama için onay veren okul yöneticileri, Google formlar üzerinden Helsinki Deklarasyonuna uygun olarak hazırlanan bilgilendirilmiş onam formu ve çalışmanın amacının yer aldığı anketlerin bağlantı linkini WhatsApp üzerinden rehber öğretmenlere iletmişlerdir. Rehber öğretmenler WhatsApp üzerinden bağlantı linkini öğrenciler ve velileri ile paylaşmışlardır. Gönüllü olarak çalışmaya katımayı kabul eden, herhangi bir fiziksel, bilişsel veya psikolojik engeli olmayan, velileri onam veren tüm öğrenciler Google formlar üzerindeki anketleri doldurmuşlardır. Tekrarlı katılımları engellemek için Google formlardaki ankete öğrenci numarası da eklenmiş, böylece anketi tekrar dolduran öğrencilerin ilk değerlendirmesi çalışmaya alınmıştır. Anket uygulama süresi 10-15 dakika sürmüştür.

Veriler; Ergenler için Tanıtıcı Özellikler Formu, Siber Zorbalık ve Internet Saldırganlığı Tarama Anketi (SZISTÖ) ve İnternet Bağımlılığı Ölçeği (IBÖ) ile Google formlar yardımı ile toplanmıştır.

\section{Veri Toplama Araçları}

\section{Ergenler için Tanıtıcı Özellikler Formu}

Bu formda; yaş, cinsiyet, aile tipi, sınıf, gelir durumu, anne eğitim durumu, baba eğitim durumu gibi ergenlerin tanıtıcı özelliklerine ilişkin sorular ve internet kullanım amacı, hafta içi ve hafta sonu kullanım süresi, evde internet varlığı, bilgisayar varığı gibi teknoloji kullanımına ilişkin özelliklerin yer aldığı 24 soru bulunmaktadır.

\section{Siber Zorbalık ve Internet Saldırganlığını Tarama Ölçeği (SZISTÖ)}

Hinduja ve Patchin (2009) tarafından geliştirilen ölçeğin Türkçe uyarlanması Özdemir ve Akar (2011) tarafından yapıImıştır. SZISTÖ, Siber Zorba Kurbanı OIma (SZKO) (9 madde) ve Siber Zorba Olma (SZO) (9 madde) alt ölçeklerinden oluşan 5'li likert tipte bir ölçektir $(20,21)$. Ölçekten alınan puan arttıkça siber zorba kurbanı/mağduru olma ve siber zorba olma durumunun arttığı gözlenmektedir. Türkçe geçerlikgüvenirlik çalışmasında ölçeğin SZKO alt ölçeğinin Cronbach Alpha değeri=0.79; SZO alt ölçeğinin Cronbach Alpha değeri $=0.94$ olarak belirtilmiştir (22). Bu çalışmada Cronbach Alpha değerleri sırasıyla olarak 0.82 ve 0.76 hesaplanmıştır.

\section{İnternet Bağımlılık Ölçeği (iBÖ)}

Lise öğrencilerinin internet bağımlıı̆̆ düzeyi, Hahn ve Jerusalem (2001) tarafından geliştirilen, Şahin ve Korkmaz (2011) tarafından Türkçeye uyarlanan, 5'li likert tipte olan İB̈ kullanılarak belirlenmiştir. Ölçek toplam 19 madde ve 5 alt ölçekten (Kontrol Kaybı, Vazgeçme Belirtileri, Bağımlııkta Süre Artışı, Çalışma ve Verimlilikte Olumsuz Sonuç ve Sosyal Illişkilerde Olumsuz Sonuçlar) oluşmaktadır. Ölçekten alınan yüksek puan (20-51 puan: Düşük internet bağımlıığı, 52-67 puan: orta internet bağımlı̆ı̆̆, 68-100 puan: yüksek internet bağımlılığı) internet bağımlılığının arttığını göstermektedir. Ölçeğin alt ölçek Cronbachs Alpha değerlerinin 0.81-0.83 arasında değiştiği ve toplam ölçek Cronbachs Alpha değerinin 0.93 olduğu belirtilmiştir $(23,24)$. Bu çalışmada ise toplam ölçek Cronbachs Alpha değeri 0.94 olarak hesaplanmıştır.

\section{Veri Analizi}

Verilerin analizi IBM SPSS Statistics 21.0 (IBM SPSS Inc, Chicago, ILL, USA) paket programı ile değerlendirilmiştir. Araştırmada tanımlayıcı veriler; yüzdeler, ortalamalar ve standart sapmalar $(x \pm \mathrm{Sd})$ ile gösterilmiştir. Verilerin normalliğini değerlendirmek için Shapiro-Wilk testi, histogram ve $Q-Q$ grafikleri kullanılmıştır. Ergenlerin internet kullanım sıklığının SZisTÖ Siber Zorba Kurbanı OIma ve Siber Zorba Olma Alt Ölçek Puan Ortalamaları üzerine etkisi Kruskal Wallis testi ile değerlendirilmiştir. İnternet Bağımlılı̆ı Ölçeği (IBÖ) toplam puan ve alt ölçekler ile Siber Zorbalık ve İnternet Saldırganlığı Tarama Ölçeği (SZisTÖ) 
toplam puanı arasındaki ilişki Spearman korelasyon analizi ile belirlenmiştir. Anlamlılık düzeyi $p<0.05$ kabul edilmiştir.

\section{Bulgular}

Çalışmaya katılan lise öğrencilerinin \%59.0'ının kız, \%54.0'ının 9. sınıf, \%74.5'i 2-3 kardeşe sahip ve \%60.6'sının ailelerinin gelirleri gidere denktir. Öğrencilerin annelerinin \%78.6'sının annelerinin çalışmadığı, \%46.5'inin ilkokul mezunu olduğu, babalarının \%33.5'inin lise mezunu olduğu ve tamamının çalışı̆̆ı belirlenmiştir. Çalışmaya katılan öğrencilerin yaş ve günlük uyku süreleri ortalamasının sırasıyla $15.26 \pm 1.19$ yll ve $8.52 \pm 1.65$ saat olduğu tespit edilmiştir (Tablo 1).

\section{Tablo 1. Ergenlerin tanıtıcı özellikleri}

\begin{tabular}{|c|c|c|}
\hline Tanitıcı özellikler & $S$ & $\%$ \\
\hline \multicolumn{3}{|l|}{ Cinsiyet } \\
\hline Kadın & 322 & 59 \\
\hline Erkek & 224 & 41 \\
\hline \multicolumn{3}{|l|}{ Sinıf } \\
\hline 9 & 295 & 54.0 \\
\hline 10 & 151 & 27.7 \\
\hline 11 & 50 & 9.2 \\
\hline 12 & 50 & 9.2 \\
\hline \multicolumn{3}{|l|}{ Anne eğitim durumu } \\
\hline Illkokul & 254 & 46.5 \\
\hline Ortaokul & 109 & 20.0 \\
\hline Lise & 118 & 21.6 \\
\hline Üniversite ve üstü & 65 & 11.9 \\
\hline \multicolumn{3}{|l|}{ Baba eğitim durumu } \\
\hline İlkokul & 150 & 27.5 \\
\hline Ortaokul & 89 & 16.3 \\
\hline Lise & 183 & 33.5 \\
\hline Üniversite ve üstü & 124 & 22.7 \\
\hline \multicolumn{3}{|l|}{ Anne çalışma durumu } \\
\hline Çalışan & 117 & 21.4 \\
\hline Çalışmayan & 429 & 78.6 \\
\hline \multicolumn{3}{|l|}{ Gelir durumu } \\
\hline Gelir giderden az & 119 & 21.4 \\
\hline Gelir gidere denk & 331 & 60.6 \\
\hline Gelir giderden fazla & 96 & 17.6 \\
\hline \multicolumn{3}{|l|}{ Kardeş sayısı } \\
\hline Tek çocuk & 21 & 3.8 \\
\hline $2-3$ kardeş & 409 & 74.9 \\
\hline \multirow[t]{2}{*}{3 ve üzeri kardeş } & 116 & 21.2 \\
\hline & Ort \pm SS & Medyan (Min-Max) \\
\hline Öğrencilerin yaşları & $15.26 \pm 1.19$ & $15(12-19)$ \\
\hline Öğrencilerin günlük uyku süreleri & $8.52 \pm 1.65$ & $9(1-16)$ \\
\hline
\end{tabular}

Öğrencilerin \%32.2'sinin hafta içi 3-5 saat/gün, \%30.2'sinin hafta sonu 3-5 saat/gün internet kullandıkları, \%40.1'inin sosyal paylaşım sitelerinde (facebook, twitter, instagram, whatsapp vb.) chat yapmak için internet kullandıkları belirlenmiştir. Çalışmaya katılan lise öğrencilerinin \%57.1'nin evlerinde bilgisayar, \%35.0'ınınn tablet, \%86.3'ünün evde internet bağlantısı, \%88.6'sının akıllı telefonu olduğu ve \%71.4'ünün telefonlarında internetlerinin olduğu saptanmıştır (Tablo 2).

Öğrencilerin \%6.1'inin sanal ortamlarda, \%5.9'unun cep telefonu mesajı şeklinde ve \%4.8'inin sohbet odasında siber zorbalık kurbanı oldukları belirlenmiştir. Lise öğrencilerinin \%4.2'sinin sohbet odasında, 
\%2.6'sının cep telefonu mesajı şeklinde ve \%2.4'ünün sanal ortamlarda siber zorbalık yaptığı saptanmıştır (Tablo 3).

Tablo 2. Ergenlerin teknoloji kullanımına ilişkin özellikleri

\begin{tabular}{|c|c|c|}
\hline Teknoloji kullanımına ilişkin özellikler & S & $\%$ \\
\hline \multicolumn{3}{|l|}{ Hafta içi internet kullanma sıklığı } \\
\hline$<1$ saat/gün & 35 & 6.4 \\
\hline 1-3 saat/gün & 168 & 30.8 \\
\hline 3-5 saat/gün & 176 & 32.2 \\
\hline 5-7 saat/gün & 78 & 14.3 \\
\hline$>7$ saat/gün & 89 & 16.3 \\
\hline \multicolumn{3}{|l|}{ Hafta sonu internet kullanma sıklığı } \\
\hline$<1$ saat/gün & 46 & 8.4 \\
\hline 1-3 saat/gün & 146 & 26.7 \\
\hline 3-5 saat/gün & 165 & 30.2 \\
\hline 5-7 saat/gün & 89 & 16.3 \\
\hline$>7$ saat/gün & 100 & 18.3 \\
\hline \multicolumn{3}{|l|}{ İnternet kullanım amacı } \\
\hline Oyun oynamak için & 93 & 17.0 \\
\hline $\begin{array}{l}\text { Sosyal paylaşım sitelerinde chat yapmak için (facebook, twitter, instagram, } \\
\text { whatsapp vb.) }\end{array}$ & 219 & 40.1 \\
\hline Film ve dizi izlemek için & 124 & 22.7 \\
\hline Araştırma ve ödev yapmak için & 77 & 14.1 \\
\hline Hepsi & 25 & 4.6 \\
\hline Diğer & 8 & 1.5 \\
\hline \multicolumn{3}{|l|}{ Evde bilgisayar bulunma durumu } \\
\hline serat & 312 & 57.1 \\
\hline Yok & 234 & 42.9 \\
\hline \multicolumn{3}{|l|}{ Tablet varlığı } \\
\hline Var & 191 & 35.0 \\
\hline Yok & 355 & 65.0 \\
\hline \multicolumn{3}{|l|}{ Evde internet bağlantısı varlığı } \\
\hline Var & 471 & 86.3 \\
\hline Yok & 75 & 13.7 \\
\hline \multicolumn{3}{|l|}{ Akıllı telefon varlığı } \\
\hline Var & 484 & 88.6 \\
\hline Yok & 62 & 11.4 \\
\hline \multicolumn{3}{|l|}{ Telefonda internet varlığı } \\
\hline Var & 390 & 71.4 \\
\hline Yok & 156 & 28.6 \\
\hline \multicolumn{3}{|l|}{ İnternet bağımlılığı durumları $(n=479)$} \\
\hline Düşük internet bağımlılığı & 404 & 84.3 \\
\hline Orta internet bağımılı̆̆ı & 53 & 11.1 \\
\hline Yüksek internet bağımlılığı & 22 & 4.6 \\
\hline
\end{tabular}

Hafta içi ve hafta sonu internet kullanım süresi $>7$ saat/gün olan lise öğrencilerinin SZiSTÖ SZKO ve SZO alt ölçek puan ortalamalarının daha yüksek olduğu belirlenmiştir $(p<0.05)$ (Tablo 4).

Çalışmada kullanılan her bir ölçeğin kendi alt ölçekleri arasındaki yüksek düzeyde anlamlı bir ilişki bulunmuştur. IBÖ ve ZSISTÖ arasındaki ilişki incelendiğinde; öğrencilerin İÖ kontrol kaybı alt ölçeği ile SZISTÖ-SZKO ve SZO toplam puanı arasında ise düşük düzeyde anlamlı bir ilişki olduğu belirlenmiştir $(p<0.01)$. IBÖ sosyal olumsuzluk alt ölçeği ile SZiSTÖ-SZKO ve SZO alt ölçek puanları arasında ise düşük düzeyde bir ilişki olduğu saptanmıştır $(p<0.01)$. Lise öğrencilerinin IBÖ toplam puanı ile SZiSTÖ-SZKO ve SZO alt ölçek puanları arasında düşük düzeyde anlamlı bir ilişki bulunmuştur ( $p<0.01)$ (Tablo 5). 
Tablo 3. Öğrencilerin SZisTÖ siber zorba kurbanı olma ve siber zorba olma durumlarının frekans dağılımları

\begin{tabular}{|c|c|c|c|}
\hline $\begin{array}{l}\text { SZISTÖ Siber Zorba Kurbanı OIma } \\
(n=57)\end{array}$ & Sayı (\%) & SZiSTÖ Siber Zorba OIma ( $n=25)$ & Sayı (\%) \\
\hline Sohbet odasında & $25(4.8)$ & Sohbet odasında & $23(4.2)$ \\
\hline Mail olarak & $6(1.1)$ & Mail olarak & $2(0.4)$ \\
\hline $\begin{array}{l}\text { Bilgisayardayken anlık mesajlar } \\
\text { olarak }\end{array}$ & $9(1.7)$ & $\begin{array}{l}\text { Bilgisayardayken anlık mesajlar } \\
\text { olarak }\end{array}$ & $4(0.7)$ \\
\hline Cep telefonu mesajları olarak & $31(5.9)$ & Cep telefonu mesajları olarak & $14(2.6)$ \\
\hline Cep telefonuyla & $2(0.4)$ & Cep telefonuyla & $10(1.8)$ \\
\hline Resimli ya da görüntülü mail olarak & $4(0.8)$ & Resimli ya da görüntülü mail olarak & $3(0.5)$ \\
\hline Myspace/Instagram'da & $22(4.1)$ & Myspace/Instagram'da & $9(1.7)$ \\
\hline Facebook'da & - & Facebook'da & $2(0.4)$ \\
\hline $\begin{array}{l}\text { Myspace/Instagram ya da facebook } \\
\text { dışında başka sosyal paylaşım } \\
\text { sitelerinde }\end{array}$ & $7(1.3)$ & $\begin{array}{l}\text { Myspace/instagram ya da facebook } \\
\text { dışında başka sosyal paylaşım } \\
\text { sitelerinde }\end{array}$ & $4(0.7)$ \\
\hline Twitter'da & - & Twitter'da & - \\
\hline Youtube'da & $6(1.1)$ & Youtube'da & $4(0.7)$ \\
\hline Sanal ortamlarda & $33(6.1)$ & Sanal ortamlarda & $13(2.4)$ \\
\hline $\begin{array}{l}\text { Interaktif oyun sitelerinde (tavla, } \\
\text { islambil, okey, satranç vb.) }\end{array}$ & $11(2.1)$ & $\begin{array}{l}\text { Interaktif oyun sitelerinde (tavla, } \\
\text { islambil, okey, satranç vb.) }\end{array}$ & $3(0.5)$ \\
\hline Playstation vb. oynarken & $7(1.3)$ & Playstation vb. oynarken & $9(1.7)$ \\
\hline
\end{tabular}

Tablo 4. Ergenlerin internet kullanım sıklıklarına göre SZisTÖ siber zorba kurbanı olma ve siber zorba olma alt ölçek puan ortalamaları

\begin{tabular}{|c|c|c|c|c|}
\hline \multirow[t]{2}{*}{ Internet kullanım skklkkları } & \multicolumn{2}{|c|}{ SZiSTÖ Siber Zorba Kurbanı OIma } & \multicolumn{2}{|c|}{ SZISTÖ Siber Zorba OIma } \\
\hline & Ort $\pm S S$ & $\begin{array}{c}\text { Medyan } \\
\text { (Min-Max) }\end{array}$ & Ort $\pm S S$ & $\begin{array}{c}\text { Medyan } \\
\text { (Min-Max) }\end{array}$ \\
\hline \multicolumn{5}{|c|}{ Hafta içi internet kullanma sıklığı } \\
\hline$<1$ saat/gün & $9.20 \pm 0.53$ & $9(9-11)$ & $9.22 \pm 0.68$ & $9(9-12)$ \\
\hline 1-3 saat/gün & $9.29 \pm 0.93$ & $9(9-16)$ & $9.63 \pm 2.07$ & $9(9-24)$ \\
\hline 3-5 saat/gün & $9.32 \pm 1.04$ & $9(9-19)$ & $9.66 \pm 2.08$ & $9(9-28)$ \\
\hline 5-7 saat/gün & $9.65 \pm 1.93$ & $9(9-21)$ & $10.24 \pm 2.64$ & $9(9-24)$ \\
\hline$>7$ saat/gün & $10.07 \pm 2.13$ & $9(9-19)$ & $10.95 \pm 4.15$ & $9(9-36)$ \\
\hline Test & $K W=11.607$ & $p=0.021$ & $K W=22.339$ & $p=0.000$ \\
\hline \multicolumn{5}{|c|}{ Hafta sonu internet kullanma sıkığı } \\
\hline$<1$ saat/gün & $9.34 \pm 0.82$ & $9(9-13)$ & $9.54 \pm 1.45$ & $9(9-17)$ \\
\hline 1-3 saat/gün & $9.28 \pm 1.08$ & $9(9-19)$ & $9.63 \pm 2.24$ & $9(9-24)$ \\
\hline 3-5 saat/gün & $9.41 \pm 1.34$ & $9(9-19)$ & $9.62 \pm 1.67$ & $9(9-21)$ \\
\hline 5-7 saat/gün & $9.32 \pm 0.76$ & $9(9-12)$ & $9.95 \pm 2.63$ & $9(9-28)$ \\
\hline$>7$ saat/gün & $10.07 \pm 2.21$ & $9(9-21)$ & $10.97 \pm 4.09$ & $9(9-36)$ \\
\hline Test & $K W=10.236$ & $p=0.037$ & $K W=19.910$ & $p=0.001$ \\
\hline
\end{tabular}

Tablo 5. İnternet Bağımlılığı Ölçeği (IBÖ) toplam puan ve alt ölçekler ile Siber Zorbalık ve İnternet Saldırganlığı Tarama Ölçeği (SZiSTÖ) toplam puanı arasındaki korelasyon

\begin{tabular}{|c|c|c|c|c|c|c|}
\hline & 1. & 2. & 3. & 4. & 5. & 6. \\
\hline İBÖ Kontrol Kaybı & 1 & & & & & \\
\hline İB̈ Sosyal Olumsuzluk & $.746^{\star \star}$ & 1 & & & & \\
\hline İÖ Online Kalma & $.768^{\star \star}$ & $.747^{\star \star}$ & 1 & & & \\
\hline İBÖ Toplam & $.947^{\star \star}$ & $.877^{\star \star}$ & $.893^{\star \star}$ & 1 & & \\
\hline 5. SZISTÖ Siber Zorba Olma & $.204^{\star \star}$ & $.189^{\star \star}$ & $.172^{\star \star}$ & $.212^{\star \star}$ & 1 & \\
\hline 6. SZisTÖ Siber Zorba Kurbanı OIma & $.226^{\star \star}$ & $.248^{\star \star}$ & $.191^{\star \star}$ & $.236^{\star \star}$ & $.326^{\star \star}$ & 1 \\
\hline
\end{tabular}




\section{Tartışma}

Son zamanlarda bilişim teknolojilerinin hayatın her alanına girmesi, ilişkilerin sanal ortamlara aktarılması nedeniyle özellikle ergenler interneti çok fazla kullanabilmektedir. Bu çalışmaya katılan lise öğrencilerinin \%32.2'sinin hafta içi 3-5 saat/gün, \%30.2'sinin hafta sonu 3-5 saat/gün internet kullanmaları ve \%40.1'inin sosyal paylaşım sitelerinde chat yapmak için (facebook, twitter, instagram, whatsapp vb.) internet kullanmaları bu durumu destekler niteliktedir. Ayrıca çalışmaya katılan lise öğrencilerinin evlerinde bilgisayar (\%57.1), tablet (\%35), evde internet bağlantısı (\%86.3), akıllı telefon (\%88.6) ve telefonlarında internetlerinin olması (\%71.4), internet ve bilişim teknolojilerine daha kolay erişim sağladıklarını düşündürmektedir. İnternet ve çevirimiçi oyunlara tablet, telefon gibi cihazlardan da ulaşılabiliyor olması ergenlerde daha fazla ve daha kolay bir şekilde internete ulaşma imkanı sağlamaktadır $(3,25)$. Bu durum her ne kadar bir avantaj olsa da, așırı ve kontrolsüz internet kullanımını da beraberinde getirmektedir. Ünver ve Koç (2017) ile Yüksel ve Yılmaz (2016), internet kullanım süresi arttıkça, siber zorbalık, problemli internet kullanımı ve riskli internet davranışlarının arttığını belirlemişlerdir $(26,27)$. Bu çalışmada da, lise öğrencilerinin internet bağımlılık düzeyleri ile SZISTÖ-SZKO ve SZO alt ölçek puanları arasında düşük düzeyde bir ilişki bulunmuştur $(p<0.01)$ (Tablo 5). Ayrıca hem hafta içi hem de hafta sonu $>7$ saat/gün internete giren öğrencilerin SZiSTÖ-SZKO ve SZO alt ölçek puanları daha yüksek bulunmuştur. Bu durum özellikle pandemi döneminde internette geçirilen zamanın artması ile, ergenlerin internet aracılığı ile sosyal çevrelerine daha kolay ulaştıkları, daha fazla yabancı kişi ile iletişim kurabildikleri, daha fazla pornografik içeriğe maruz kaldıkları şeklinde yorumlanabilir. Chang ve arkadaşları da, internet bağımlı̆̆g olan ergenlerin daha yüksek düzeyde çevrimiçi riskler (pornografi / şiddete maruz kalma, siber zorbalık ve çevrimiçi cinsel taciz) ve sağlık riskleri (daha az sebze / meyve alımı, daha fazla şekerli içecek tüketimi, sigara, alkol tüketimi, düşük özgüven ve depresyon) yaşadıklarını belirtmişlerdir (28). Internetin aşırı ve kontrolsüz kullanımı, internet bağımlıı̆ı, siber zorbalık ve mağduriyet gibi olumsuz durumlar için risk oluşturabilmektedir $(29,30)$.

İnternette yer alan online dünyanın az kısıtlayıcı olması, gizli olabilmesi, internette kimliğini gizleyebilme durumu da özellikle kimlik arayışında olan ergenlerin daha çok ilgisini çekebilmektedir (31-33). Tüm bunlar ergenleri siber zorba olma ve siber mağduriyet açısından riskli hale getirebilmektedir. Siber zorbalık bilgi ve iletişim araçlarını kullanarak bir kişiye ya da gruba yapılan kasıtlı ve rahatsız edici davranışlardır $(5-7,34)$. Kötü içerikli SMS ya da anlık iletiler gönderme, sanal ortamda kişi hakkında dedikodu yayma, kişiye özel bilgileri, rahatsız edici görüntüleri paylaşma sanal zorbalık türlerinden bazılarıdır $(5,7,34,35)$. Bu çalışmada da öğrencilerin \%6.1'inin sanal ortamlarda, \%5.9'unun cep telefonu mesajı şeklinde ve \%4.8'inin sohbet odasında siber zorbalık mağduru oldukları belirlenmiştir. Ayrıca lise öğrencilerinin \%4.2'sinin sohbet odasında, \%2.6'sının cep telefonu mesajı şeklinde ve \%2.4'ünün sanal ortamlarda siber zorbalık yaptığı saptanmıştır. Deniz ve Çalışgan, öğrencilerin en fazla siber zorba ve siber zorba kurbanı oldukları sanal ortamın "facebook" olduğunu belirlemişlerdir (36). Lise öğrencilerinin zorbalık deneyimlerinin incelendiği başka bir çalışmada, öğrenciler sosyal medya platformlarında ve cep telefonu mesajı ile siber zorbalığa maruz kaldıklarını ifade etmişlerdir (34).

Bu araştırma sadece Karadeniz Bölgesinde bir il merkezinde bulunan lise öğrencileri üzerinde yapılmıştır. Farklı illeri ve bölgeleri kapsayacak çalışmalar yapılabilir. Pandemi nedeniyle araştırma verileri yüz yüze toplanamamış, Google formlar kullanılarak toplanmıştır.

Sonuç olarak pandemi nedeniyle, sosyal ilişkilerin kısıtlanması, eğitimin online yürütülmesi, özellikle gençlerde internet kullanım süresini, dolayısıyla siber zorbalık riskini artırmaktadır. Bu çalışmada da, hafta içi ve hafta sonu internet kullanım süresi $>7$ saat/gün olan lise öğrencilerinin SZiSTÖ̈-SZKO ve SZO alt ölçek puanlarının yüksek olduğu bulunmuştur. Ayrıca lise öğrencilerinin IBÖ toplam puanı ile SZiSTÖ-SZKO ve SZO alt ölçek puanları arasında düşük düzeyde anlamlı bir ilişki saptanmıştır. Bu nedenle öğrencilere, ailelere ve öğretmenlere internet bağımlığı, internette yaşanabilecek riskler, internetin bilinçli ve sağıklı kullanma ve siber zorballık konusunda okul yönetimi/personeli sağllk profesyonellerinin işbirliği ve okul rehberlik servisleri araclığılla bilgilendirici seminerler yapılabilir. Ayrıca, Z kuşağının özellikleri ve pandemi 
sürecindeki internet kullanımının artıı̆ı dikkate alındığında, farkındalık arttııcı müdahale çalışmalarının yapııması internet bağımlılı̆ı ve siber zorbalık/mağduriyet gibi durumların yaşanmasını azaltabilir.

\section{Kaynaklar}

1. Baltacı Ö, Akbulut ÖF, Yılmaz E. Problemli internet kullanımında güncel bir risk faktörü: Covid-19 pandemisi. Uluslararası Psikolojik Danışma ve Rehberlik Araştırmaları Dergisi 2021; 3(1): 97-121.

2. Göker ME, Turan Ş. Covid-19 pandemisi sürecinde problemli teknoloji kullanımı. ESTÜDAM Halk Sağı̆̆̆ Dergisi 2020; 5(COVID-19 Özel SayISI): 108-114.

3. Yavuz 0. Ergenlik döneminde internet bağımllı̆̆ının okul başarısı üzerinde etkileri. Uluslararası Toplum Araştırmaları Dergisi 2018; 8(15): 1056-1080.

4. Hanehalkı Bilişim Teknolojileri (BT) Kullanım Araştırması, 2020. https://data.tuik.gov.tr/Bulten/Index?p=Hanehalki-Bilisim-Teknolojileri-(Bt) Kullanım-Arastırmasi-2020-33679 (Accessed 05.05.2021).

5. Patchin JW, Hinduja S. Bullies move beyond the school yard: A preliminary look at cyberbullying. Youth Violence Juv Justice 2006; 4(2): 148-169.

6. Aksaray S. Siber zorbalık. C..Ü. Sosyal Bilimler Enstitüsü Dergisi 2011; 20(2): 405-432.

7. Uluçay DM, Melek G. Türkiye'deki okullarda siber zorbalık: Bir literatür değerlendirmesi. Online Academic Journal of Information Technology 2017; 8(30): 91-106.

8. Özbey H, Başdaş Ö. Ergenlerde zorbalık ve hemşirelik yaklaşımı. ERÜ Sağlık Bilimleri Fakültesi Dergisi 2020; $7(1): 46-50$.

9. Craig W, Boniel-Nissim M, King N, Walsh SD, Boer M, Donnelly PD, et al. Social media use and cyber-bullying: A cross-national analysis of young people in 42 countries. J Adolesc Health 2020; 66(6S): S100-S108.

10. Çelen Ç, Çöp E, Dinç GŞ, Hekim Ö, Göker Z, Sekmen E, et al. Çocuk psikiyatrisi polikliniğine başvuran ergenlerde akran zorbalığı ile siber zorbalık ve öfke ifade tarzlarının ilişkisi. Türkiye Çocuk Hast Derg 2020; 14 : 108-118.

11. Çimen ID. Ergenlerde siber zorbalık, internet aile tutumu ve aile işlevselliğinin etkisi. Anadolu Psikiyatri Derg 2018; 19(4): 397-404.

12. Taştekin E, Bayhan P. Ergenler arasındaki siber zorbalığın ve mağduriyetin incelenmesi. Online Journal of Technology Addiction \& Cyberbullying 2018; 5(2): 21-45.

13. Lee C, Shin N. Prevalence of cyberbullying and predictors of cyberbullying perpetration among Korean adolescents. Comput Human Behav 2017; 68: 352-358.

14. Baldry AC, Farrington DP, Sorrentino A. School bullying and cyberbullying among boys and girls: Roles and overlap. J Aggress, Maltreat Trauma 2017; 26(9): 937-951.

15. Eroğlu $Y$, Aktepe $E$, Akbaba $S$, Işı $A$. Özkorumak $E$. Siber zorbalık ve mağduriyetin yaygınlığının ve risk faktörlerinin incelenmesi. Eğitim ve Bilim 2015; 40(177): 93-107.

16. Genç AK, Avcı E. Binomial (oran) verilerin meta-analizi: Türkiye'deki internet bağımlılık oranının belirlenmesi. Erzincan Üniversitesi Fen Bilimleri Enstitüsü Dergisi 2020; 13(3): 1050-1068.

17. Ceyhan E. Ergen ruh sağlığı açııından bir risk faktörü: İnternet bağımlılığı. Çocuk ve Gençlik Ruh Sağıı̆ı Dergisi 2008; 15: 109-116.

18. Tahiroğlu AY, Celik GG, Uzel M, Ozcan N, Avci A. Internet use among Turkish adolescents. Cyberpsychol Behav 2008; 11(5): 537-543.

19. Aslan N. Ergenlerde internet bağımlılı̆ı, yaygınlığı, nedenleri ve sonuçları üzerine bir araştırma. Uluslararası Sosyal Araştırmalar Dergisi 2019; 12(65): 945-957.

20. Söyler S, Kaptanoğlu AY. Sanal uyuşturucu: İnternet. Gümüşhane Üniversitesi Sağllk Bilimleri Dergisi 2018; 7(2): $37-46$.

21. Hinduja S, Patchin, JW. Bullying Beyond The Schoolyard: Preventing and Responding to Cyberbullying. Thousand Oaks, CA: Sage Publications (Corwin Press), 2009.

22. Özdemir M, Akar F. Lise öğrencilerinin siber zorbalığa ilişkin görüşlerinin bazı değişkenler bakımından incelenmesi. Kuram ve Uygulamada Eğitim Yönetimi Dergisi 2011; 17(4): 605-626.

23. Hahn A, Jerusalem M. Internetsucht: Reliabilität und validität in der online-Forschung. Theobald A, Dreyer M, Starsetzki T (editors), Handbuch zur Online-Marktforschung. Beiträge aus Wissenschaft und Praxis. Wiesbaden: Gabler, 2001: 213-233.

24. Şahin C, Korkmaz Ö. İnternet Bağımlılığı Ölçeği'nin Türkçe'ye uyarlanması. Selçuk Üniversitesi Ahmet Keleşoğlu Eğitim Fakültesi Dergisi 2011; 32: 101-115. 
25. Ayhan B, Köseliören M. Internet, online oyun ve bağımllık. Online Journal of Technology Addiction \& Cyberbullying 2019; 6(1): 1-30.

26. Ünver $H$, Koç Z. Siber zorbalık ile problemli internet kullanımı ve riskli internet davranışı arasındaki ilişkinin incelenmesi. Türk Eğitim Bilimleri Dergisi 2017; 15(2): 117-140.

27. Yüksel M, Yılmaz E. Lise öğrencilerinin internet bağımlılık düzeyleri ile problem çözme becerileri arasındaki ilişkinin çeşitli değişkenler açısından incelenmesi. İlköğretim Online 2016; 15(3): 1031-1042.

28. Chang FC, Chiu, $\mathrm{CH}$, Lee $\mathrm{CM}$, Chen, $\mathrm{PH}$, Miao, NF. Predictors of the initiation and persistence of internet addiction among adolescents in Taiwan. Addict Behav 2014; 39(10): 1434-1440.

29. Samaha M, Hawi NS. Relationships among smartphone addiction, stress, academic performance, and satisfaction with life. Comput Human Behav 2016; 57: 321-325.

30. Altundağ Y. Lise öğrencilerinde sanal zorbalık ve problemli internet kullanımı ilişkisi. Online Journal of Technology Addiction \& Cyberbullying 2016; 3(1): 27-43.

31. Doğan U, Çolak TS. Self-concealment, social network sites usage, social appearance anxiety, loneliness of high school students: A model testing. Journal of Education and Training Studies 2016; 4(6): 176-183.

32. Griffiths M. Sex on the internet: Observations and implications for internet sex addiction. J Sex Res 2001; 38(4): 333-342.

33. Gross EF. Adolescent internet use: What we expect, what teens report. J Appl Dev Psychol 2004; 25(6): 633649.

34. Dinç ES. Sosyal medya ortamlarında siber zorbalık: Lise öğrencilerinin siber zorbalık deneyimlerinin incelenmesi. Yeni Medya Elektronik Dergi 2020; 4(1): 24-39.

35. Sticca F, Perren S. Is cyberbullying worse than traditional bullying? Examining the differential roles of medium, publicity, and anonymity for the perceived severity of bullying. J Youth Adolesc 2013; 42(5): 739-750.

36. Deniz L, Çalışgan H. İlköğretim öğrencilerinde internet bağımlıı̆ı ve siber zorbalık. Route Educational and Social Science Journal 2015; 2(4): 399-422.. 